\title{
Que no sea otra de las mismas
}

Entre el segundo lustro de los años setenta y la década de los ochenta hubo en Colombia un explosivo incremento del número de facultades de medicina pasando de unas 20 a unas 55 o 60 . Me cuento entre los que estudiamos medicina con la idea de servir incondicionalmente a las gentes como una vocación y como me lo encomendó mi padre cuando le conté que quería ser médico: «Muy bueno mijo que estudie medicina para que le sirva a la gente», sin cortapisa alguna y, como tal, lo cumplí.

En ese entonces creía y hoy estoy inclinado a creer que el sueño de la mayoría de los que quieren ser médicos poco ha cambiado: atender enfermos, formular medicamentos, ordenar exámenes, practicar cirugías, trabajar en un hospital y, además, adquirir un posicionamiento social y económico o los dos, según el caso. Pero casi nunca a nadie se le ha ocurrido sacar a los aspirantes a sucesores de Hipócrates, Galeno o Asclepio de esa sesgada concepción de la profesión médica únicamente como reparadora de los efectos de la enfermedad e indicarles que el objetivo primario de la medicina es el mantenimiento y cuidado de la salud individual y colectiva. Recuerdo que en el primer encuentro con estudiantes de medicina del primer semestre, más de la mitad del grupo ya expresaba sus deseos de ser especialistas en alguna rama clínica o quirúrgica, pero ninguno expresaba inclinación hacia la medicina preventiva.

La más alta proporción del pénsum de pre y posgrado, de ayer y de hoy, se destina a estudiar la génesis, los efectos y las secuelas de las enfermedades y solamente en unas pocas semanas, que merecen poca atención, se imparte una somera información sobre la salud pública y la medicina preventiva, cuyo objetivo es evitar la enfermedad, diagnosticarla y tratarla oportunamente, reparar las secuelas y, en fructífera alianza multisectorial, promover estilos de vida saludables y poner en práctica las condiciones fundamentales para proporcionar la mejor calidad de vida a los asociados. Así mismo, aunque muchas veces se dice que la investigación debe ser el eje de los estudios médicos, la inducción a esta actividad no es que sea tan significativa. Ni que decir de lo poco o nada que de manera sistemática se insiste sobre la atención humanitaria al paciente. Se repite que el personaje más importante de un servicio médico, hospitalario o ambulatorio, es el paciente, pero este asunto sigue mostrando vacíos.

El modelo de educación médica, hasta donde mi historia personal me lo permite y un poco más allá, no ha tenido muchos cambios, básicamente se sigue en la tendencia de la medicina reparativa, ganando cada día más terreno la idea de especializarse, la utilización a menudo innecesaria de los maravillosos adelantos tecnológicos, de enorme valor cuando se usan racionalmente.

Pero también ha perdido vigencia el médico general, que es la puerta de entrada a un sistema racional de salud, porque es el profesional que debe estar muy cercano al paciente como sucesor que es del médico de familia que gozó de gran estima en el pasado; ese médico también debe estar más comprometido con la promoción de la salud y la prevención de la enfermedad y como cabeza de un equipo básico de atención sanitaria debe estar en capacidad de solucionar de manera eficiente y eficaz hasta un $80 \%$ de los quejas de los que acuden a las consultas, tal como era, tan demostrable como evidente, antes de entrar en vigencia el Sistema de Seguridad Social bien concebido, pero deficientemente aplicado.

El médico social, como se autodenomina Saúl Franco, en su columna habitual en un diario nacional, en mayo pasado, con el título «Para formar mejores médicos» escribió: «No es lo mismo producir médicos que fabricar 
computadores. Ni formar médicos para la Edad Media que para la sociedad actual», hecho, que sin ser discutible, no parece recibir la importancia merecida.

Y continúa Franco: «Pero tampoco es independiente la formación médica de los avances científicos, las tensiones sociales o los valores dominantes. Al contrario, en un proceso complejo y cambiante, cada sociedad forma médicos según los conceptos que tiene de salud-enfermedad-vida-muerte, al ritmo de las tensiones político-sociales, de los avances científico-tecnológicos, y a la medida de sus capacidades y posibilidades». Conceptos que en buena parte se pueden compartir. Cuenta también en esa columna que los ministerios de Salud y Educación conformaron un grupo de trece personas para que hicieran recomendaciones sobre posibles transformaciones de la educación médica en Colombia, el cual presentó sus conclusiones en un documento de 42 páginas donde consignaron 104 recomendaciones. Es posible que cuando lo conozca sea objeto de algunas reflexiones escritas.

Recuerdo que desde comienzos de los años 70 del siglo anterior, entidades asistenciales y universitarias se han preguntado cuál es el médico que necesita Colombia. De los promotores de varias facultades de medicina oí decir que querían desarrollar una institución de donde egresaran médicos diferentes. Nunca encontré una respuesta satisfactoria ni pude corroborar lo segundo.

Ojalá que la nueva Facultad que ahora promueven en Antioquia dos instituciones, una hospitalaria y otra universitaria, logren producir un profesional diferente y que sea el que requiere el país. Sin dejar de preguntar: ¿otra más sí se necesita y será diferente? ¡Qué corra el tiempo!

José De los Ríos Osorio 